\title{
ENTROPY-INFORMATIONAL APPROACH TO ANALYSIS OF SELF-OGRANIZATION OF BANKING SYSTEM
}

\author{
Natalia Tkachuk \\ Department of Finance, Banking and Insurance \\ SHEI "University of Banking" \\ 1 Andriivskaya str., Kyiv, Ukraine, 04070 \\ kamashik@ukr.net
}

\begin{abstract}
The evolving economy today is non-stationary in the nature of its character of behavior which becomes the reason of emergence of imbalances and instability of the market environment that cause the emergence of nonlinear processes in functioning of the banking system which may carry a threat to its development. Super fast tempos of change in the globalized world generate flows of institutional and innovative disturbances that test banks and banking systems for viability and encourage them to study the peculiarities of their behavior in terms of non-linearity and non-equilibrium. Knowledge and interpretation of synergetic properties of the banking system today have not only theoretical but also practical significance for development and implementation of the concept of self-organization of banks.

The theoretical questions of mutual influence and interconnection of entropy and information on the processes of self-organization in the banking system are considered. The functioning of the banking system in an unstable environment with chaotic and orderly behavioral stages is characterized by a nonlinear dynamics of entropy, as well as a significant dependence on the influence of management information that enters the system. Saturation of the banking system with this information makes it possible to force out chaos from it, it increases its orderliness and effect of functioning.

From the point of view of entropy and informational approach, the nature and conditions of self-organization in the banking system are disclosed. It was established, that fundamental condition for self-organization in the banking system is to transfer the system to a non-equilibrium state when it becomes quite sensitive to external disturbances. It is noted, that entropy represents a measure of disorder of the system, and its growth increases chaos and can lead to devastating consequences in the functioning of the system. The processes of self-organization in the banking system will only be possible if its order is growing.
\end{abstract}

Keywords: banking system, self-organization, synergetics, entropy, information, non-equilibrium.

\section{Introduction}

Today, it is generally acknowledged by the science, that the nature of behavior of economic systems is far from inviolable sequence of homogeneous states, since in its operation slow and fast stages, consolidation, formation and disintegration of structures are harmoniously combined. In consequence the orderly behavior of the system is broken; even very weak disturbances become supersensitive which can give rise to a fundamentally different mode of behavior of the constituent elements of the evolving system. In the context of synergetics, the non-equilibrium economic system over time is subject to complex transformations and it acquires an orderly regime of functioning.

Under the powerful press of global and national institutional factors the functioning environment of the banking system is filled with various fluctuations that affect its functioning and the behavior of its elements (banks). In particular, there is a growing risk of increasing chaos, uncertainty and weakening of stability of functioning, worsening of competitiveness and increasing likelihood of bankruptcy of banks. Under such conditions the development of the banking system is increasingly gaining signs of nonlinearity with characteristic sudden changes of vectors, slow and fast phases of movement.

The evolutionary development of the banking system is characterized by a dynamic "game" of chaos and order, which in consequence under certain circumstances, self-organization processes in the system become possible. This causes the necessities for clearing up of economic nature and the characteristic features of entropy dependence of functioning of the banking system from the amount of management information, introduced into its environment. Except from that consideation of the features of the banking system with the use of synergistic theory postulates will allow us to analyze the essence of the mechanism of its self-organization in a non-stationary market environment. 
Afterwards, the task of understanding of the nature, argumentation of the preconditions and the nature of self-organization processes in the banking system, taking into account cybernetic ideas about entropy, information and processes of self-organization, becomes indisputable and relevant. For understanding the nature of self-organization in the banking system it is necessary to find and analyze the relationship between the entropy indicators, the accumulated information and the state of functioning of the system, taking into account duality of chaos and order.

\section{The aim of the study}

The aim of the article is grounding of the theoretical aspects of interplay and interconnection of entropy and information with the processes of self-organization in the banking system.

\section{Materials and methods of research}

The growing needs of economic theory and practice stipulate the development of theoretical and methodological substantiation and instrumentation for ensuring the effective development of the banking system in the conditions of nonlinearity, instability and constant fluctuations of the external environment.

Achievement of the goal of the study foresees involvement of classical and modern views concerning the banking system as a kind of a complex non-linear system that is capable of self-organization. In spite of a wide range of scientific studies, in our opinion, there is no complete conceptual development of analytical tools for studying the activities of banks in nonequilibrium, unpredictable market environment.

Within the framework of the set goal the research of the following tasks will be solved:

- to consider the economic nature of self-organization of the banking system as a kind of a complex economic system;

- to clear up the influence of entropy and information on the processes of self-organization;

- to reveal characteristic features of nonlinear processes which occur in the banking system under conditions of the entropy environment of its functioning.

The theoretical basis of the study of self-organization of the banking system in the nonlinear market environment forms information theory, synergetics, chaos, disasters, as well as systematic and special methods of thermodynamics, statistical physics in particular: the methods of abstract analysis, logical generalizations, analogies and comparisons, mathematical dependencies.

\section{Experiments}

The determining condition for the optimal functioning of the banking system is its non-equilibrium self-organization which is difficult to predict by classical methods and approaches. The concept of self-organization was first introduced in 1947 and at its initial stages its essence was investigated in the natural sciences. The learning of interaction and self-organization of complex systems is a key component of postclassical science; it covers the study of fractals, theory of dissipative structures, deterministic chaos, complexity, self-organized criticality and synergetics.

The deep regularity of functioning of complex systems which is capable of self-organization lies in combination of two contradictory tendencies: aspiration for the growth of entropy and negentropy which lies in the basis of evolution of systems. The famous scientist J. Gig called such a feature of self-developing systems "dualism" [1]. Its manifestation is the dependence of the state of a complex system from the predominance of entropy or negentropy tendencies as a result of which in the system can either occur a process of decline and its transition to a lower level of existence, or conversely, the system can develop to a higher level. Therefore it should be noted, that the formation of the essential load of the concept of self-organization was largely contributed to the study of synergy, which subsequently began to be considered as a theory of self-organization in academic circles.

Deepening into the causes of the processes of self-organization of complex economic systems, it can be noted, that the basis of self-organization is the dialectic part and the whole in the system, and the mechanisms of its formation are constant contradictions between stable development of the system on the one hand, and coherent processes, coordination and co-operation of 
elements of the system on the other hand. Thus, A. P. Rudenko suggests distinguishing two types of self-organization of the system:

1) the continual self-organization of the components and subsystems of the system;

2) the coherent self-organization of the system.

For the first type of self-organization the development of the system can occur not only due to the co-operative interaction of homogeneous elements of the system, but also due to the kinetic continuum of elements with system and dynamic links between them. Thus, it becomes possible to use the notion of self-organization not only in relation to systems, but also in relation to its separate constituent elements. The scientist even suggests calling such a direction as syncretics [1]. In this case, the market mechanism is considered as chaos which is necessary for the development of the economic system.

The founder of synergetics, the German scientist G. Hacken, noted that "a system, capable of self-organization, should be considered as a system that without any specific external influence independently forms any spatial, temporal and functional structure" [2]. A group of researchers, led by V. N. Volkova, believe that systems that have the ability to self-organization and self-development have a number of chains and features that are due to the presence of active elements; have a dual nature: there are new properties that are useful for the existence of a system that ensures its adaptability to changing environmental conditions, but at the same time cause uncertainty in the development of the system and complicate its management [3].

The wider definition is from the system theory guide: "Self-organization is the ability of complex systems to reach a new level of development, and in particular, they in a greater degree show such qualities as the ability to withstand entropy (self-destructive) processes and develop non-aggressive (ordered) tendencies for adapting to changing conditions, transforming if necessary its structure and maintaining a certain level of stability" [4].

Taking into account the works of the well-known scientists and researchers in this direction, we note that self-organization represents itself as the process of ordering of spatial and temporal environment in the open economic system at the expense of interaction of a plural number of elements that form it without specific influence of external factors; as a result of which there are elements of a new, qualitative level. In contrast to the organization as a systemic feature, characterized by equilibrium ordering of the elements of the system, self-organization, as synergistic characteristics is distinguished by non-equilibrium ordering of the components of the system [5].

Using the proofs of G. Hacken, we note that to all processes occurring in open nonlinear systems, self-organization is inherent, while the system can generate stationary and non-stationary dissipative structures that are capable of "transforming" the energy of the system in a certain way, and due to this its radically new qualities and properties arise [6]. Consequently, the content and the key vector of evolution of the system are determined, first of all, by its own substantial nature, and the influence of external factors is predominantly secondary. Of course, exceptions are possible - in such cases external factors do not accelerate or slow down the internal self-organization of the system but radically change its character. Then the system either transforms, preserving some succession with its past state or becomes qualitatively new. But in any case it remains dissipative, that is, such that dissipates energy from the outside. Thus, the evolution of any complex system, including the banking system, is actually a process of self-organization.

\section{Results and discussion}

The conditions for market transformations are accompanied by a growing influence on the banks' activity by the flow of destructive disturbances that can cause chaotic behavior of the economic system as a whole and the banking system in particular. As a result, the banking system undergoes qualitative changes and restructuring: the fast and slow phases of development are shifted, system structures are created and disappeared.

In non-equilibrium environments the loss of energy is compensated by its inflow from the outside, precisely because of this the process of self-organization of the system takes place. The basic condition for the process of self-organization of the banking system is transfer of the system to a non-equilibrium state which is possible only if the system exchanges with its external 
environment material, energy, financial and information flows and is quite sensitive to external disturbances. At that, it should be taken into consideration that under the condition of nonlinearity of such processes, even very small external fluctuations due to their multiple repetitions and strengthening can generate large-scale structural changes in the system. The order in the non-equilibrium system can be formed from chaos in which, as a result of scattering of energy, a dissipative structure appears which in turn is associated with a significant decrease in energy of the system and an increase in its entropy.

In the historical retrospective study of interpretation of the essence of the entropy behavior of complex systems such well-known researchers in thermodynamics and statistical physics as R. Clausius, L. Boltzmann, J. Gibbs, M. Smolukhovsky were engaged. Thus, having introduced into scientific circle the notion of entropy, R. Clausius found that in a closed system it remains either constant (reversible processes), or it increases (irreversible processes) [7]. In giving entropy probabilistic interpretation, L. Boltzmann proved that "any closed system tends to a definite end state for which entropy will be maximal" [8].

It should be noted, that entropy represents itself as a measure of disorder and uncertainty of the system which is stipulated by the level of complexity of its development. At the same time entropy depends on how we consider the system and how much information is known about its functioning [9, 10]. That is why it is logical that with intensification; and enlargement of entropy, it becomes difficult to understand the logics of behavior of the concrete phenomenon, situation or system.

The opposite in content to entropy is the notion of negentropy which means the degree of orderliness and organization of the system. According to J. Gibbs thoughts, the reduction of entropy in the system is possible only if it is filled with energy that is able to withstand the growth of chaos in the system. This interpretation of entropy later led to a clear argumentation of influence of entropy on the state of order and equilibrium of the system. In this regard, E. Schroedinger neatly notes that negative entropy, taken with a negative sign, is in itself a measure of orderliness of the system; therefore, an increase in negative entropy (negentropy) can be considered as a means of weakening of disorderliness which can lead to the destruction of the system [12].

Concerning banking system as a complex economic system of micro-level, the reduction of entropy and ordering in it is possible on the basis of introduction of a control system of information from the NBU (National Bank of Ukraine) which has a coordinating influence on its elements (banks) and determines their collective behavior in the system. As the practice affirms, the timely and adequate response of the NBU to any unexpected and unfavorable changes in the external conditions of functioning of banks can arrange functioning of the banking system; improve the efficiency of the use of financial resources and the quality of services, rendered by banks.

The dependence between entropy, orderliness, and the amount of information in the system has been studied in detail by the classics of cybernetics. In particular

N. Wiener noted: "The amount of information in the system is a measure of its organization and entropy itself is a measure of its disorganization; it is the same entropy but taken with the opposite sign" [13, p. 56]. Later the supporters of such ideas were L. von Bertlanfy, S. Bir, L. Briluen, K. Shannon, W. Ashby, and others.

In the 60 's of the $20^{\text {th }}$ century the academician V.A. Trapeznikov grounded on the basis of his own studies the exponential relation between entropy and disordered system. From the position of statistical physics, he proved that the relationship between entropy $(\mathrm{H})$ and disorder of the system (B) has the form [14]:

$$
\frac{B}{B^{*}}=e^{\frac{-\left(H^{*}-H\right)}{a}} \text {, }
$$

where $\mathrm{B}^{*}$ is disorder of the system in its original state; $\mathrm{H}^{*}$ is entropy of the system in the initial state; a is some constant.

It is necessary to emphasize the attention on the point that from the position of the theory of information it represents the eliminated uncertainty of behavior of the system and is numerically equal to the reduction of this uncertainty. Let in the initial state the banking system was in a 
chaotic state with a maximum entropy $\left(\mathrm{H}_{\mathrm{m}}\right)$, then the amount of the seized information would be determined as follows [15]:

$$
\mathrm{I}=\mathrm{H}_{\mathrm{m}}-\mathrm{H},
$$

where I is the number of the seized information; $\mathrm{H}_{\mathrm{m}}$ is the maximum possible entropy of the source of information; $\mathrm{H}$ is entropy of the source of information;

Then, formula (1) can be represented as follows [12, 15]:

$$
\frac{B}{B^{*}}=e^{\frac{-I}{a}}
$$

Disorder of the banking system (B) is characterized by the number of possible micro-states, and the amount of information (I) is equivalent to the value of entropy and has a probabilistic interpretation. From the position of V. A. Trapeznikov, information, available in the economic system is distributed as follows: one part is substantiated during the process of banks' activity in the terms of labor, the rest is accumulated in the form of knowledge, and another part of the information is used in the process of banking business to combat disorder of the system in management of it [14].

In the banking system information comes not only from the NBU in the process of management and regulation of the activities of banks, but also in the form of decisions taken, compiled reports, it is also materialized in the objects and means of labor in the form of embodied knowledge, and the other part is used to combat disorderliness. As far as satiation of information of the process of organization and management of the banking system increases, the disorderliness of its functioning decreases. The efficiency of functioning of the system increases with the decrease of disorder in it, and vice versa - it decreases in the event of the spread of chaos in the system.

In the search for a measure of order in the system the well-known researcher G. Furst proposed to use relative entropy which initially was revealed by the founder of the theory of information K. Shenon [12]:

$$
\mathrm{R}=1-\left(\mathrm{H} / \mathrm{H}_{\mathrm{m}}\right)
$$

where $\mathrm{N}$ is entropy of the source of information; $\mathrm{H}_{\mathrm{m}}$ is the maximum possible entropy of the source of information; $\mathrm{R}$ is the order of ordering (relative entropy).

As we can see, the value of the $\mathrm{R}$ index can be in the range from 0 to 1 , so its limiting values correspond to the absent order in the system, they characterize the degree of entropy if the value of the $\mathrm{R}$ index is equal to 0 , and characterize the perfect order when the $\mathrm{R}$ index is equal to 1 .

In the case of too high entropy in the system (when $\mathrm{H}=\mathrm{H}_{\mathrm{m}}$ ) and the system is in the maximum stage of chaos, the index of order is zero, that is $\mathrm{R}=0$, and vice versa, when entropy $(\mathrm{H}=0)$ and the order in the system increases, then the corresponding index gets the maximum possible value: $\mathrm{R}=1$. As self-organization of the system foresees rising of the level of order in it, then the rate of change of the $\mathrm{R}$ index should be positive. As it is known, the increase (change) of any independent variable is identified with its differential, and then self-organization of the economic system will be possible following the observance of such a condition [14]:

$$
\frac{\mathrm{dR}}{\mathrm{dt}}>0
$$

Taking into account Formula 1 and having conducted its differentiation, we obtain the following inequality [14]:

$$
\frac{\mathrm{dR}}{\mathrm{dt}}=-\frac{\mathrm{H}_{\mathrm{m}} \frac{\mathrm{dH}}{\mathrm{dt}}-\mathrm{H} \frac{\mathrm{dH_{ \textrm {m } }}}{\mathrm{dt}}}{\mathrm{H}_{\mathrm{m}}^{2}}>0 .
$$


Taking into account that the denominator of the fraction (3) will always be positive $\left(\mathrm{H}_{\mathrm{m}}^{2}>0\right)$, we obtain the condition for the implementation of the inequality (2), that is, the condition for carrying out self-organization of the banking system [14, p. 343]:

$$
\mathrm{H} \frac{\mathrm{dH}}{\mathrm{dt}}>\mathrm{H}_{\mathrm{m}} \frac{\mathrm{dH}}{\mathrm{dt}} \text {. }
$$

Consequently, the process of self-organization of the evolving banking system will only be possible in one case, when chaos in the behavior of the system is inferior to the growing order. That is, self-organization of the system foresees that the differential of entropy $(\mathrm{dH})$ must be less than the differential of maximum entropy $\left(\mathrm{dH}_{\mathrm{m}}\right): \mathrm{dH}<\mathrm{dH}_{\mathrm{m}}$, which will mean a relative increase in ordering in the system. Such main features of the banking system are:

- non-stationary (nonlinearity) of parameters and stochastic behavior of the elements of the system;

- uniqueness and unpredictability of the system's behavior in specific conditions of market development;

- ability of the system to adapt to changes in the environment;

- ability of the system to withstand entropy (destructive) tendencies and to detect negentropy tendencies;

- ability of the system to develop goal setting when the goals of functioning are formed internally on the basis of internal patterns of system development;

- ability and desire of the system to achieve a goal when the goals of functioning are formed internally on the basis of internal patterns of the development of the system;

- attempts of the system to use energy and resources not only for supporting stability and firmness, but also for ensuring their unbalanced state [5].

An important consequence of interaction is also the fact that the banking system is characterized by topology (continuity and connectivity). So, important is not only how much the power of managerial influence is, but also how much its proper spatial organization is.

\section{Conclusions}

The study of theoretical aspects of self-organization of the banking system, conducted by us, with taking into account the entropy and information influence makes it possible to note the following:

1. The principle of systemic self-organization is one of the most essential elements of a holistic synergetic economic paradigm which allows seeing the identity of the laws of self-organization, irrespective of the area in which they occur. The perfect philosophy of self-organization, formed on the basic laws of thermodynamics, is fully applicable to the study of the behavior of economic systems. According to synergetic approach, the processes of self-organization of complex systems are based on the state of initial chaos. As in any other sphere of organizational changes, the processes of self-organization include the stages of normalization of chaotic states of system structures which depend on the degree of saturation of the system of management information and the degree of its entropy.

2. The research of self-organization in the field of market relations of the modern banking system fully confirms expectations of synergistic effects. In our work we proceed from the assumption that adaptive development of the banking system is based on the extraction of information from the external environment of its operation and its use for the fastest adaptation of the system to external disturbances. During implementation of such an information process, the banking system itself tries to assess the nature and level of penetrating obstacles, as well as the consequences of their impact on its development. According to the results of this analysis, the system takes decisions, aimed at neutralizing or mitigating the negative influence of perturbations on the state of the system on its target trajectory of development.

3. The modern banking system has an entropy and informational nature, the essence of which is manifested in the fact that with the increase in its accumulated management information, 
it decreases its entropy and increases the level of organization and increases the efficiency of activities. The complex influence of the values of maximum entropy of the banking system, the amount of information, inherent in the system, and the degree of its order forms the dynamics of the effect of functioning of the banking system. Investigation of the banking system as a kind of a complex economic system, where the laws of self-organization are in force, is today in line with the latest trends in the development of science in general and reflects the true movement of researchers.

\section{References}

[1] Rudenko, A. P. (2013). Samoorganizatsiya i sinergetika. Slozhnyye sistemy, 2, 3-39.

[2] Haken, G. (2014). Informatsiya i samoorganizatsiya. Makroskopicheskiy podhod k slozhnyim sistemam. Moscow: Lenard Publ, 320.

[3] Volkova, V. N., Denisov, A. A. (2014). Teoriya sistem i sistemnyiy analiz. Moscow: Yurayt Publ, 616.

[4] Volkovoy, V. N., Emelyanova, A. A. (Eds.) (2006). Teoriya sistem i sistemnyiy analiz v upravlenii organizatsiyam. Moscow: Finansyi i statistika, 848.

[5] Yakimtsov, V. V. (2015) Osnovni printsipi teorii samoorganizatsii (sinregetiki). Ekonomika i finansi, 12, 42-50.

[6] Haken, G. (2015). Sinergetika. Principy i osnovy. Perspektivy i prilozheniia. Chast’ 2. Perspektivy i prilozheniia. Ierarhii neustoichivostei v samoorganizuiushhihsia sistemah i ustroistvah. Moscow: Lenard, 432.

[7] Karno, S., Tomson, U. (lord Kelvin), Klauzius, R., Boltsman, L., Smoluhovskiy, M.; Timiryazev, A. K. (Ed.) (2007). Vtoroe nachalo termodinamiki. Moscow: LKI Publ, 312.

[8] Vedenyapin, V. V., Adzhiyev, S. Z. (2014). Entropiya po Boltsmanu i Puankare. Uspekhi matematicheskikh nauk, 69 (6 (420)), 45-80. doi: http://doi.org/10.4213/rm9635

[9] Shterenberg, M. I. (2013). Entropiya - smysl i izmereniye. Slozhnyye sistemy, 2 (7), 82-91.

[10] Shterenberg, M. I. (2002). The place of synergetics in science. Scientific and technical information processing, 29 (4), 19-22.

[11] Prigozhin, I., Stengers, I. (2014). Poryadok iz haosa. Novyiy dialog cheloveka s prirodoy. Moscow: Editorial UKSS, 296.

[12] Chuprov, S. V. (2017). Entropy-Information Analysis of Self-Organization and of the Effect of Functioning of an Industrial Economic System. Bulletin of Baikal State University, 27 (3). $443-449$. doi: http://doi.org/10.17150/2500-2759.2017.27(3).443-449 Books, 208.

[13] Wiener, N. (1989) The Human Use of Human Beings: Cybernetics and Society. Free Association

[14] Trapeznikov, V. A. (1983). Upravlenie i nauchno-tehnicheskiy progress. Moscow: Nauka Publ, 224.

[15] Ahmedatt, T., Azroul, E., Hjiaj, H., Touzani, A. (2018). Existence of entropy solutions for some nonlinear elliptic problems involving variable exponent and measure data. Boletim Da Sociedade Paranaense de Matemática, 36 (2), 33-55. doi: http://doi.org/10.5269/bspm.v36i2.30581

[16] Akimchenko, A. A., Aletdinova, A. A., Bukhval'd, E. M., Babkin, A. V., Chuprov, S. V. et. al. (2017) Ekonomika i menedzhment v usloviyakh nelineinoi dinamiki. Saint Petersburg: Peter the Great Saint Petersburg Polytechnic University Publ., 773.

[17] Denisenko, V. I., Reshetov, I. V. (2009). Model i printsipy primeneniya mekhanizmov samoorganizatsii v sotsialno-ekonomicheskikh sistemakh. Nelineynyy mir, 8, 626-638.

[18] Tsvetkov, V. Ya. (2017). Emerdzhentizm. Mezhdunarodnyy zhurnal prikladnykh i fundamentalnykh issledovaniy, 2, 137-138.

[19] Tsvetkov, V. Ya. (2013). Information interaction. European researcher. Series A, 62 (11-1), 2573-2577.

[20] Tsvetkov, V. Ya., Lobanov, A. A. (2014). Big Data as Information Barrier. European researcher, Series A, 78 (7-1), 1237-1242. 